\title{
Variation in Lupinus arboreus alkaloid profiles and relationships with multiple herbivores
}

\author{
Lynn S. Adler ${ }^{\mathrm{a}, *}$, Pamela M. Kittelson ${ }^{\mathrm{b}}$ \\ a Department of Biology, Virginia Polytechnic Institute and State University, 2119 Derring Hall, \\ Blacksburg, VA 24061 USA \\ b Department of Biology, Gustavus Adolphus College, $800 \mathrm{~W}$. College Avenue, \\ St. Peter, MN 56082 USA
}

Received 14 January 2003; accepted 22 November 2003

\begin{abstract}
Variation in plant defensive profiles can be affected by environmental factors, genetic factors, and their interactions, and different feeding guilds may have different responses to variation in defenses. Here we present results of a factorial breeding design in Lupinus arboreus from three sites of origin to determine how parental effects, population differences, and environmental effects influence alkaloid profiles and resistance to multiple herbivores. Alkaloids were identified and quantified in seeds and adult plants grown at each of the three sites. We also censused five different herbivores on plants over 2 years and determined the relationship between each herbivore density and total alkaloids, alkaloid profiles, plant size and site. We found strong effects of origin, maternal parent, and maternal $\times$ paternal interactions on seed alkaloid profiles, and effects of origin, destination site, their interactions, and maternal $\times$ paternal interactions on leaf alkaloid profiles. However, there was no correlation between alkaloid concentration or specific compounds in seeds and full-sib adult plants. Density of the leaf galler Dasineura lupinorum and the fungus Colletotrichium spp. was affected by total alkaloid concentration and alkaloid profiles, while density of apical flies and bud gallers was not affected by any alkaloid measure. Red and green forms of the leaf galler had different responses to alkaloids, and green leaf gallers and fungi had opposite responses to measures of alkaloid profiles. These results highlight the complexity of interactions between herbivores and plant defenses, and indicate that measuring selection for defense traits may not be straightforward in natural environments that include multiple herbivore guilds.
\end{abstract}

(C) 2004 Elsevier Ltd. All rights reserved.

Keywords: Defensive compounds; Defense allocation; Genotype $\times$ environment interactions; Herbivore guild; Leaf galler; Lupine; Maternal effects; Quinolizidine alkaloids

\footnotetext{
${ }^{*}$ Corresponding author. Tel.: +1-540-231-8946; fax: +1-540-231-9307.

E-mail address: 1sadler@vt.edu (L.S. Adler).
} 


\section{Introduction}

The composition and concentration of defensive compounds in individual plants is determined by a variety of environmental factors (Hagele and Rowell-Rahier, 1999; Ralphs and Gardner, 2001; Skaanild et al., 2001), including season (Feeny, 1970; Dement and Mooney, 1974; Schultz et al., 1982; Bowers et al., 1992), site elevation (Carey and Wink, 1994), resource availability (Johnson et al., 1989; Nitao et al., 2002) and previous herbivory (Karban and Baldwin, 1997), as well as genetic variation between populations (Bowers et al., 1992; Wink and Carey, 1994; Berenbaum and Zangerl, 1998) and individuals (Berenbaum and Zangerl, 1992). Thus, individual phenotypic variation can be a result of genetic variation, environmental variation, and their interactions (Falconer, 1989). However, studies examining the heritability of defensive compounds typically use controlled environments to minimize environmental variation (e.g. Agren and Schemske, 1993; van Dam and Vrieling, 1994), or use clones (e.g., Maddox and Root, 1987), preventing the estimation of non-additive genetic effects (but see Nuñez-Farfán and Dirzo, 1994; Orians et al., 1996; Roche and Fritz, 1997, for studies that estimate narrow-sense heritability in the field). Few studies have simultaneously examined how environmental variation, population-level genetic differences, and maternal and paternal effects contribute to variation in defensive compounds.

Defensive compounds are not equally deterrent to all herbivores (Berenbaum et al., 1986; Lindroth et al., 1988; Berenbaum et al., 1989; Stout and Bostock, 1999), and not all herbivores have equivalent effects on plant fitness (Marquis, 1992). While one or two herbivores might have the largest effects on plant fitness, most plants suffer from herbivores representing many different guilds, including leaf feeders, gallers, stem borers, or seed predators. The role of defensive compounds against leaf feeding herbivores has received the most attention (Rosenthal and Berenbaum, 1991), although guilds of herbivores such as root borers (Brown, 1988; Strong et al., 1995; Maron, 1998), seed predators (Louda and Potvin, 1995) and apical meristem feeders (Juenger and Bergelson, 1997) may also have strong fitness effects. For example, Strong et al. (1995) found a positive correlation between the number of root boring Hepialus californicus larvae and the rate of lupine mortality, and decreases of $H$. californicus densities by half led to a $44 \%$ increase in lupine seed set (Preisser, 2003). Excluding below-ground herbivory for 3 years increased cumulative lupine seed set by $31 \%$ and decreased mortality by $18 \%$ (Maron, 1998). Leaf herbivores remove on average only 5-15\% of leaf area, but can have strong fitness effects on susceptible individuals (Marquis, 1992). The differential effects of diverse herbivore species, combined with spatial or temporal variability in herbivore load, can result in fluctuating selection pressures on defensive profiles in plants (Thompson, 1997).

Although within-plant variation in defense has been extensively studied (e.g. Denno and McClure, 1983), the correlation between levels of defense in different tissues is rarely examined. For example, do highly defended seed produce highly defended plants (see Agrawal et al., 1999; Agrawal, 2001)? We might expect such correlations to exist if similar processes mediate defense production in different 
tissues. Persistence of maternal effects on seed defense allocation to adulthood might also produce such correlations. Alternatively, if separate physiological or genetic processes determine seed and leaf alkaloid production, or if environmental factors strongly influence leaf alkaloid production, correlations between seed and leaf alkaloids may not exist. Such correlations between defense levels in different tissues could be beneficial if alkaloids have broad-spectrum effects against most herbivores, or could constrain the ability of plants to evolve different strategies against seed predators and other herbivores.

Plants rarely make only single defensive compounds; typically a whole suite of related compounds as well as many types of unrelated compounds are present in a single plant. The synergistic effects of these compounds may have different effects on herbivores than each compound studied in isolation (Wittstock and Gershenzon, 2002). For example, mixtures of two essential oils were up to nine times more toxic to Spodoptera litura larvae than would have been predicted based on additive effects (Hummelbrunner and Isman, 2001). Variability in defensive compounds can provide increased resistance to herbivores (Adler and Karban, 1994; Karban et al., 1997). The diversity of alkaloids was correlated with levels of lycaenid herbivory in individual perennial lupines (Dolinger et al., 1973), suggesting that such variability may play a role in lupine defense against herbivory.

Many Lupinus species, including Lupinus arboreus (yellow bush lupine) produce secondary metabolites called quinolizidine alkaloids. Quinolizidine alkaloids have broad-spectrum effects against pathogens, insects, and vertebrate herbivores (Mankinen et al., 1975; Wink, 1992; Wink and Latz-Bruning, 1995). The population of $L$. arboreus at our study site experiences spatial and temporal variability in herbivory and damage to individual plants and among lupine stands can vary dramatically. For example, in some years lupines at some sites are almost completely defoliated by tussock moth caterpillars (Orgyia vetusta) while lupines in other sites support few caterpillars and sustain little to no damage (Harrison and Maron, 1995; Strong et al., 1995). L. arboreus may evolve resistance to herbivory due to the high risk of mortality and female fitness reduction due to damage on flowers, fruit and seeds (Davison and Barbour, 1977; Strong et al., 1995; Maron and Simms, 1997; Maron, 1998; Strong et al., 1999). However, many different types of herbivores feed on L. arboreus, including insect guilds that feed on roots, leaves, flowers and seeds, as well as mammals such as deer, voles, mice and gophers (Maron and Simms, 1997; Maron, 2001). The diversity of herbivory on L. arboreus may lead to diffuse rather than pairwise coevolution if the pattern of selection on alkaloids by one herbivore changes in the presence of additional herbivores (Hougen-Eitzman and Rausher, 1994; Iwao and Rausher, 1997; Stinchcombe and Rausher, 2001).

In this study, we determined the extent to which parental effects, population differences, and environmental variation determined quinolizidine alkaloid variability of $L$. arboreus seeds and leaves, and we related alkaloid variation to the presence of four phylogenetically diverse insects and one fungus. Specifically, we addressed the following questions: 
1. How do maternal parent, paternal parent, seed origin and their interactions affect variation in seed alkaloids?

2. How do maternal parent, paternal parent, seed origin, destination site and their interactions affect variation in alkaloids of 2.5-year old plants?

3. Is there a phenotypic correlation between alkaloid levels in seeds and full-sib adult plants?

4. How is the density of herbivores from different guilds affected by total leaf alkaloids and alkaloid composition, as well as site and plant size?

\section{Materials and methods}

\subsection{Study organism and sites}

Yellow bush lupine, Lupinus arboreus Sims (Fabaceae), is a perennial, nitrogenfixing shrub that occurs along portions of the Californian coast (Hickman, 1993). Bush lupine seedlings emerge during the rainy season from December to March. Plants grow rapidly, attaining heights of $0.5-0.7 \mathrm{~m}$ within one season, and flower in their second spring (Davison and Barbour, 1977). A previous study found that the major alkaloids of $L$. arboreus growing in Europe were sparteine (30\%), lupanine $(60 \%)$ and hydroxylupanine $(10 \%)$ in the leaves, and sparteine $(80 \%)$ and lupanine $(10 \%)$ in the seeds (Wink et al., 1995). However, that study identified alkaloids in 56 lupine species, and therefore sampled only a few plants per species.

Bush lupine is abundant at our study site on the Bodega Marine Reserve (BMR) of the University of California in Sonoma County, California, where it grows in adjacent grassland and dune habitats. Bayshore (BS) and Mussel Point (MP) are grassland sites. At Bayshore, cover and persistence of bush lupine is highly variable, with average lupine cover fluctuating from 0 to $60 \%$ over 10 -year periods (Strong et al., 1995). Fluctuations in cover may be caused by high rates of herbivore damage; stands with little fluctuation in lupine cover had the fewest Hepialus caterpillars per root (Strong et al., 1995; Maron, 1998; Maron et al., 2001). At Mussel Point, lupine cover is more extensive (45-75\%), and does not fluctuate dramatically. The third site is in the dunes (DUN), where lupine cover is sparser but relatively stable (cover ranges from 20-45\%; Bodega Marine Laboratory, unpublished data). Lupines in the dunes supported the lowest numbers of herbivores of Epinotia infuscana, Dasineura lupini, Dasineura lupinorum, Orgyia vetusta, Hepialus californicus and fungal lessions of the three sites (Kittelson, unpublished data). The three areas show fine-scale genetically based differentiation and local adaptation in life-history traits such as plant size, flowering time, fecundity and mortality (Kittelson and Maron, 2001).

\subsection{Creation of full-sib and half-sib families}

To examine both genetic and environmental influences on alkaloid profiles of $L$. arboreus, we made full- and half-sib families within each of the three sites, and planted these families into common gardens at each site. Beginning in April 1995, 
we randomly selected six pollen-donating plants (sires) to cross with five seed-producing plants (dams) within each of the three sites. We conducted crosses in a complete $6 \times 5$ factorial design. This resulted in seeds from a total of 30 full-sib, six paternal and five maternal half-sib families within each site.

To prevent natural pollination during crosses, we enclosed each maternal bush with $1 \mathrm{~m}^{3}$ pollinator exclosure tents made with white polyester tent-window fabric attached to a PVC frame. Plants were sprayed with the insecticide Sevin (Union Carbide Corp, Danbury, CT) to kill any insects that could transfer pollen. To ensure that fruit set resulted only from hand-pollination, we followed a multi-step pollination process. For the complete methodology for crossing $L$. arboreus flowers see Kittelson (1998) and Kittelson and Maron (2000). Our crossing design ensured that all seeds from the same fruit and inflorescence were full-siblings, those from different inflorescences on the same dam were maternal half-siblings, and those from different bushes that were pollinated from the same sire were paternal halfsibs. We collected seeds from our crosses from July through September 1995. Collected seeds were counted and stored at room temperature.

\subsection{Common gardens}

In spring 1995 , we established $20 \times 20 \mathrm{~m}$ common garden plots within the three study sites. We cleared common garden plots of existing shrubs, and allowed all vegetation except lupine to re-establish. In January 1996, we weighed and scarified 24 randomly selected seeds from each full-sib family and planted them into randomly assigned pots ( $38 \mathrm{~mm}$ diameter $\times 135 \mathrm{~mm}$ high). Because we hand-scarified the seeds, over $99 \%$ of all seeds germinated and there were no differences among families in germination rate (Kittelson, unpublished data). In February 1996, we transplanted these seedlings into each common garden, which contained a total of six seedlings from each of 90 families per subpopulation (540 seedlings/site $\times$ 3 sites $=1620$ seedlings per garden). Each seedling was marked, and during weekly inspections in spring we weeded gardens of any volunteer lupine seedlings.

\subsection{Collection of seed and leaf material}

After establishing the gardens, we could not obtain sufficient replicate seed samples from all 90 planted families, so we haphazardly selected a subset of 60 full sib families (20 families $\times 3$ sites) representing the full range of maternal and paternal lines. Seeds were randomly pooled from one dam to create three replicates per cross containing at least four seeds each.

Leaf material was collected from 2.5-year-old plants in October 1998, by clipping two newly expanded leaves selected haphazardly from each plant. We collected only freshly expanded leaves to reduce phenological variation in alkaloid expression. Plants of this age were used to determine if parental effects on seeds (see Section 3.2) persisted in adult perennial plants (Miao et al., 1991). Plants from each site were selected based on our seed family identities, i.e. individual plants were full-siblings to unplanted seeds analyzed for alkaloids. Due to high differential 
mortality of lupines at each site by the end of 1998, we collected 76, 34 and 14 leaf samples from the dunes, Mussel Point and Bayshore sites, respectively.

\subsection{Herbivory census}

Table 1 describes the herbivores and pathogens censused. Leaf galler and fungal lesion densities were estimated as the average of counts within four $10 \mathrm{~cm}^{3}$ quadrats per plant, and apical fly density was estimated as the number of apices affected in a random sample of five apices per plant. The leaf galler Dasineura lupinorum creates both red and green galls; these color differences may be the result of different plant responses to the galler (Fernandes and Negreiros, 2001; Ollerstam et al., 2002). We scored the presence of each gall color separately. For simplicity, we will refer to all damage as 'herbivory,' including fungal lesions. We estimated the density of each herbivore species in 1996 and 1997 at one date in May or June during the time of greatest abundance. Fungi were not censused at the Mussel Point site. Only apical flies (Epinotia infuscana) were present in sufficient numbers on our plant subsample to analyze in both years. We estimated plant size (canopy volume) by measuring plant height and two perpendicular crown diameters, so that canopy volume $=$ height $\times$ two canopy diameters.

\subsection{Alkaloid analysis}

We quantified alkaloids using gas chromatography (GC). Tissue was air-dried for several weeks and then ground with a Krups 203 coffee mill. Alkaloids were extracted following the methods of Johnson et al. (1989). The methylene chloride extract was injected into a HP 5890A gas chromatograph (Hewlett Packard, Wilmington, DE) with a DB-1 megapore capillary column $(30 \mathrm{~m}, 0.25 \mathrm{~mm}$ i.d., $0.25 \mu \mathrm{m}$ film thickness; J\&W Scientific, Folsom, CA). Alkaloids were eluted by temperature programming from 200 to $300{ }^{\circ} \mathrm{C}$ over a 10 -min period, followed by $5 \mathrm{~min}$ at $300{ }^{\circ} \mathrm{C}$. Alkaloids were quantified as percentage dry weight by comparison to a known percentage of cinchonidine added as an internal standard to each sample.

Table 1

Description of herbivores censused on $L$. arboreus at BMR

\begin{tabular}{lll}
\hline Name & Family: Order & Type of damage \\
\hline Dasineura lupini & Cecidomyiidae: Diptera & Bud galler \\
Dasineura lupinorum & Cecidomyiidae: Diptera & Leaf galler (red or green galls) \\
Epinotia infuscana & Tortricidae: Lepidoptera & Apical borer; kills meristem \\
Hepialus californicus & Hepialidae: Lepidoptera & Root borer \\
Colletotrichium spp. (fungi) & Class Deuteromycetes & Black lesions on leaves, necrosis \\
& Melanconiales: Nectriodaceae & \\
\hline
\end{tabular}




\subsection{Statistical analysis}

Most alkaloid peaks were detected only in a subset of samples and individual alkaloids were therefore non-normally distributed. Because our purpose was to determine how several factors contribute to variability in alkaloid profiles, we used principal components analysis (PCA hereafter; SAS PROC PRINCOMP) to create new orthogonal variables that were linear combinations of the original variables. The covariance matrix (mean-corrected data) was used rather than the correlation matrix (mean- and standard deviation-corrected) to preserve the original units of measurement (Sharma, 1996). Separate PCA were conducted for seed and leaf alkaloids.

To analyze alkaloid variability, we used mixed-model ANOVA with maternal and paternal parent as random effects and origin and destination site (for leaf alkaloids) as fixed effects. Maternal and paternal parent were nested within origin. We used total alkaloids and the first two PCs for seed alkaloids, and the first three PCs for leaf alkaloids. Due to high, uneven mortality, we had low replication and unbalanced samples in our leaf alkaloid data. We deleted plants from the BS origin because we had only three samples; we also could not analyze parent $\times$ site interaction terms.

We conducted mixed-model analyses using SAS PROC MIXED (SAS-Institute, 1999). Degrees of freedom for $F$-tests of fixed effects were estimated using the Satterthwaite approximation (SAS-Institute, 1999). The likelihood-ratio $\chi^{2}$ test was employed for tests of the random effects. The likelihood-ratio $\chi^{2}$ test is a one-sided single degree of freedom test of the hypothesis that the variation caused by the random effect is greater then zero (Shaw, 1987; Shaw et al., 1995; Orians et al., 1996; Roche and Fritz, 1997; Agrawal, 1998).

To determine whether seed alkaloids were correlated with leaf alkaloids in fullsib crosses, we calculated the Pearson correlation coefficients between the major alkaloids and total alkaloid content of seeds and leaves using the CORR procedure of SAS. We did this in two ways: (a) pooling leaf alkaloids across the three planting sites; and (b) pooling leaf alkaloids only from plants growing in their site of origin. In both cases, we averaged values across individuals to create full-sib means.

We analyzed the combined effect of alkaloid composition (principal components), total alkaloids, plant size, and site on the density of each herbivore species. Plant size measures were used from the year of the census for each herbivore. For all herbivore species, individuals were present on only a subset of plants and their distributions were non-normal. Therefore, we analyzed herbivore density using regression with Poisson error terms (SAS PROC GENMOD; option/ dist $=$ Poisson). We tested the goodness of fit of our data to a Poisson distribution by examining the deviance/df and comparing this value to the expected chi-square distribution. When this value exceeded the cutoff for fit to a Poisson distribution $(P<0.05)$, we corrected for over- or under-dispersion by scaling the deviance/df to a value of one (option/dscale). Scaling for overdispersion was necessary for red and green leaf gallers (Dasineura lupinorum), and scaling for underdispersion was 
necessary for fungus. When an herbivore species was present on fewer than $10 \%$ of the sampled plants, it was omitted from analysis due to low power to detect an effect. This was the case for Hepialus californicus (present in four out of 121 plants) and red leaf gallers (Dasineura lupinorum) in 1997 (present in two out of 121 plants).

\section{Results}

\subsection{Alkaloid profiles}

Using GC, we found a total of 22 peaks in the seeds and 10 in the leaves. Of these, six were excluded from further seed analysis and one from leaf analysis because they were detected in fewer than $5 \%$ of the samples. The three most consistent peaks accounted for a mean \pm s.e. of $91.9 \pm 0.4 \%$ of total seed alkaloids and $64.0 \pm 1.1 \%$ of total leaf alkaloids. These alkaloids were identified as lupanine, tetrahydrorhombifoline (THRF), and 13-hydroxylupanine using GC-MS following the methods of Adler and Wink (2001).

\subsection{Principal components analysis}

In the seeds, tetrahydrorhombifoline (THRF), lupanine, and 13-OH-lupanine comprised on average $91.9 \%$ of the total alkaloids. The first two principal components (PCs) explained $95.9 \%$ of the original alkaloid variability (Table 2). Leaf alkaloids were more variable; the three prior alkaloids and an unidentified ester of 13-OH-lupanine (retention time of $11.39 \mathrm{~min}$ ) together comprised an average of $80 \%$ of the total alkaloids, with the remainder made up primarily of other alkaloid esters. Three principal components were necessary to explain $96.5 \%$ of the variation (Table 2).

Table 2

Mean percent dry weight \pm standard error of seed and leaf alkaloids, and eigenvectors for the first principal components. Unidentified alkaloids are described by retention times in minutes. Peaks whose concentrations were less than $0.01 \%$ dry weight and with eigenvectors between -0.1 and 0.1 are omitted for simplicity

\begin{tabular}{|c|c|c|c|c|c|c|c|}
\hline \multirow[t]{2}{*}{ Alkaloid } & \multicolumn{3}{|l|}{ Seed } & \multicolumn{4}{|l|}{ Leaf } \\
\hline & $\%$ & $\mathrm{PCl}$ & PC2 & $\%$ & PC1 & PC2 & PC3 \\
\hline THRF & $2.36 \pm 0.14 \%$ & 0.76 & 0.35 & $0.73 \pm 0.03 \%$ & 0.82 & -0.48 & -0.29 \\
\hline Lupanine & $1.61 \pm 0.12 \%$ & 0.59 & -0.72 & $0.17 \pm 0.02 \%$ & 0.20 & -0.12 & 0.87 \\
\hline 13-OH-lup & $1.05 \pm 0.07 \%$ & 0.27 & 0.59 & $0.18 \pm 0.01 \%$ & 0.11 & -0.24 & 0.33 \\
\hline 9.32 & 0 & - & - & $0.03 \pm 0.004 \%$ & - & - & 0.19 \\
\hline 11.15 & $0.05 \pm 0.01 \%$ & - & - & $0.03 \pm 0.005 \%$ & - & - & - \\
\hline 11.39 & $0.01 \pm 0.003 \%$ & - & - & $0.27 \pm 0.03 \%$ & 0.52 & 0.84 & - \\
\hline 13.1 & $0.14 \pm 0.1 \%$ & - & - & $0.04 \pm 0.004 \%$ & - & - & - \\
\hline$\%$ variation & & $86.8 \%$ & $9.1 \%$ & & $68.7 \%$ & $19.5 \%$ & $8.3 \%$ \\
\hline
\end{tabular}

THRF, tetrahydrorhombifoline; 13-OH-lup, 13-hydroxylupanine. 


\subsection{Sources of variation in seed alkaloids}

Total seed alkaloids and seed profiles varied significantly between populations of origin and maternal parents (Fig. 1; Table 3). Alkaloid concentrations in seeds from the Bayshore population were more than twice as high as those from Mussel Point, which were almost twice as high as those from the dunes (Fig. 1a). In addition, maternal parent had consistent effects on seed alkaloid content and profiles (Fig. 1b; Table 3). Although there was no significant main effect of paternal parent, there were consistent maternal $\times$ paternal interactions, indicating

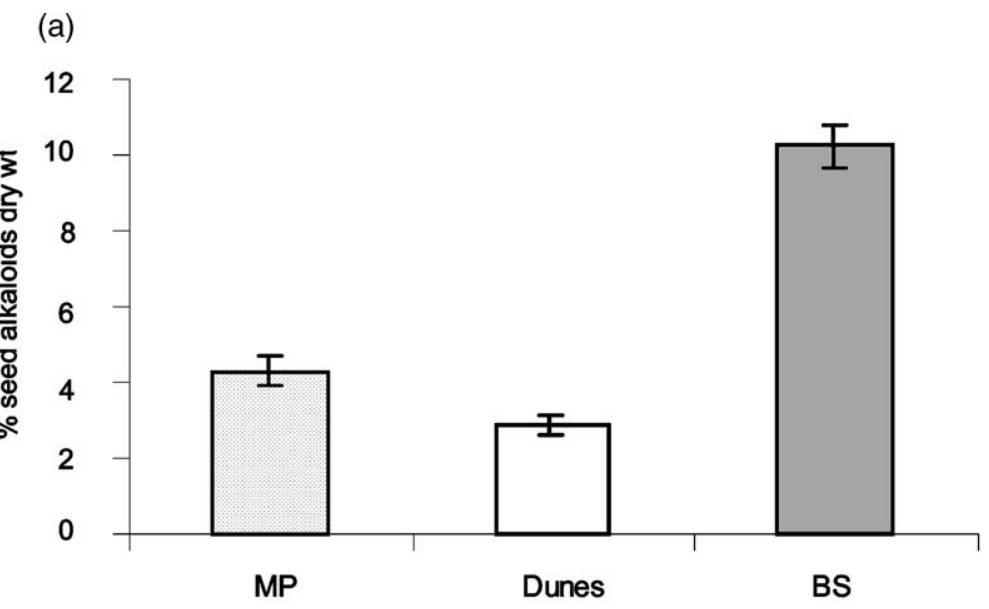

(b)

Origin

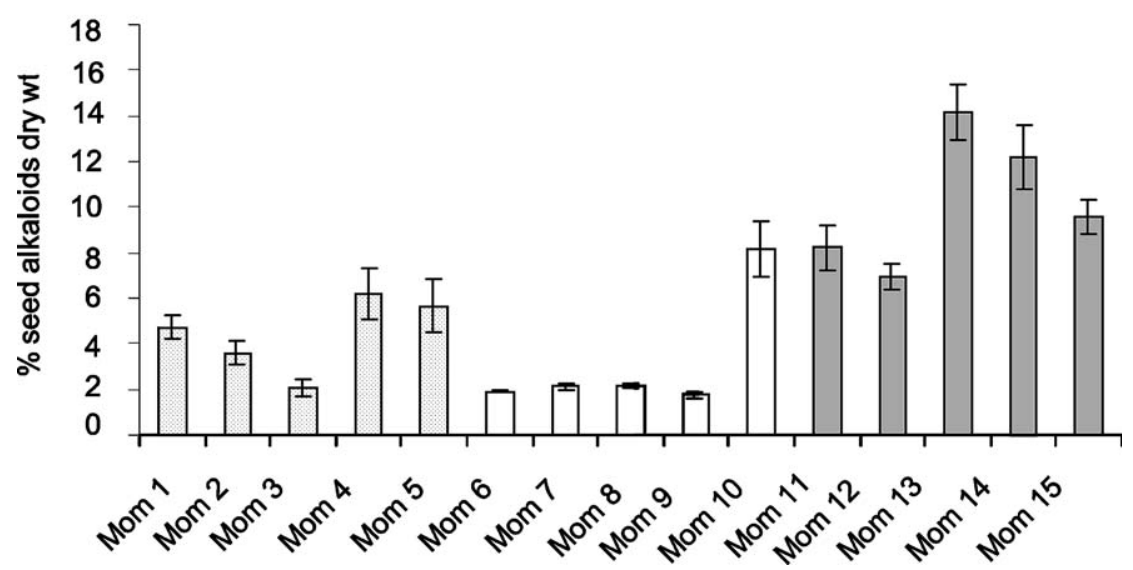

Fig. 1. Total seed alkaloids measured as percent dry weight in (a) sites of origin and (b) maternal families of L. arboreus. Error bars represent standard errors. 
Table 3

Sources of variation in seed alkaloids from the three sites of origin: Mussel Point, Bayshore, and Dunes. Mixed-model analysis for effects of maternal parent (mom), paternal parent (dad), origin and their interactions on total alkaloids and alkaloid profiles. Maternal and paternal parents were nested within origin

\begin{tabular}{|c|c|c|c|c|c|}
\hline & Source & $\mathrm{df}$ & $\mathrm{F}$ & $\chi^{2}$ & $\mathrm{P}$ \\
\hline \multirow[t]{4}{*}{ Total alkaloids } & Origin & $2,9.31$ & 11.26 & & 0.003 \\
\hline & Mom $^{\mathrm{a}}$ & 1 & & 7.9 & 0.002 \\
\hline & $\mathrm{Dad}^{\mathrm{a}}$ & 1 & & 0 & 0.500 \\
\hline & $\mathbf{M o m} \times \mathbf{D a d}^{\mathrm{a}}$ & 1 & & 110.4 & 0.0001 \\
\hline \multirow[t]{4}{*}{$\mathrm{PC} 1$} & Origin & $2,9.85$ & 10.00 & & 0.004 \\
\hline & Mom $^{\mathrm{a}}$ & 1 & & 11.7 & 0.0003 \\
\hline & $\mathrm{Dad}^{\mathrm{a}}$ & 1 & & 0.2 & 0.327 \\
\hline & $\operatorname{Mom} \times \operatorname{Dad}^{\mathrm{a}}$ & 1 & & 48.2 & 0.0001 \\
\hline \multirow[t]{4}{*}{ PC2 } & Origin & 2,12 & 0.26 & & 0.772 \\
\hline & Mom $^{a}$ & 1 & & 60.6 & 0.0001 \\
\hline & $\operatorname{Dad}^{\mathrm{a}}$ & 1 & & 0 & 0.500 \\
\hline & $\mathbf{M o m} \times \mathbf{D a d}^{\mathrm{a}}$ & 1 & & 50.9 & 0.0001 \\
\hline
\end{tabular}

Boldface type indicates $P<0.05$.

${ }^{\mathrm{a}}$ Likelihood-ratio $\chi^{2}$ tests for random effects.

that the contribution of a paternal line to seed alkaloid profile depended on which maternal line it was crossed with.

\subsection{Sources of variation in leaf alkaloids}

Origin, destination site, and their interaction all significantly influenced total leaf alkaloids and some of the principal components (Fig. 2; Table 4). On average, total leaf alkaloids were highest at Bayshore and about equivalent at the dunes and Mussel Point. However, plants from the dunes had slightly lower alkaloid pro-

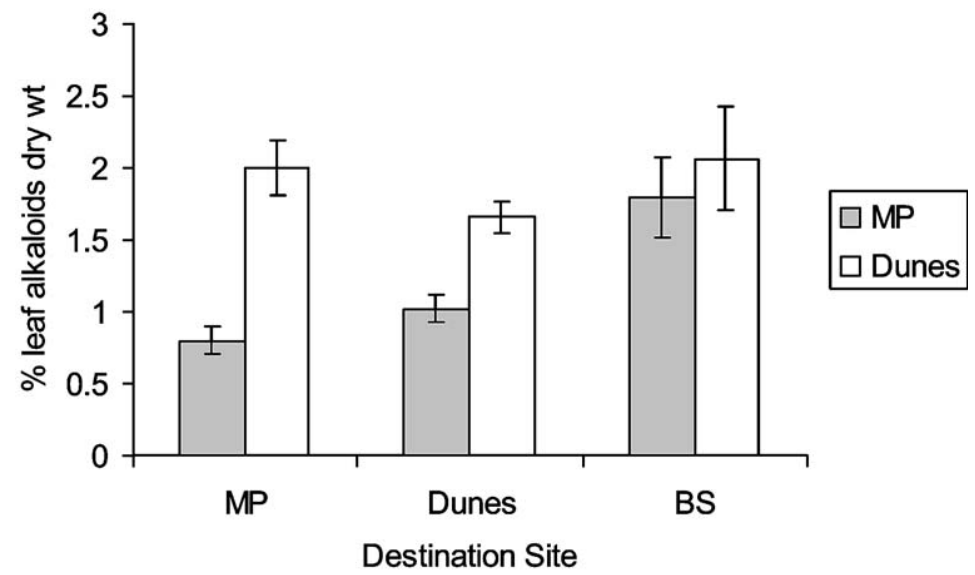

Fig. 2. The effect of origin site and destination site on leaf alkaloids, measured as percent dry weight. Error bars represent standard error. Bar patterns represent the origin sites as in Fig. 1. 
Table 4

Sources of variation in leaf alkaloids from three origin sites grown at three destination sites. Mixedmodel analysis for effects of maternal parent (mom), paternal parent (dad), seed origin and destination site (site) on total alkaloids and alkaloid profiles. Samples from the Bayshore origin were omitted due to high mortality, and interactions between parents and site were omitted due to unbalanced samples

\begin{tabular}{|c|c|c|c|c|c|}
\hline & Source & $\mathrm{df}$ & $F$ & $\chi^{2}$ & $P$ \\
\hline Total alkaloids & $\begin{array}{l}\text { Seed origin } \\
\text { Mom }^{\mathrm{a}} \\
\text { Dad }^{\mathrm{a}} \\
\text { Destination site } \\
\text { Origin } \times \text { site } \\
\text { Mom } \times \text { Dad }^{\mathrm{a}}\end{array}$ & $\begin{array}{l}\mathbf{1 , 9 . 1 8} \\
1 \\
1 \\
2,102 \\
2,102 \\
1\end{array}$ & $\begin{array}{l} \\
4.74 \\
3.97\end{array}$ & $\begin{array}{l}0.6 \\
0.1\end{array}$ & \begin{tabular}{l|}
$\mathbf{0 . 0 1 0}$ \\
0.219 \\
0.376 \\
$\mathbf{0 . 0 1 1}$ \\
$\mathbf{0 . 0 2 2}$ \\
$\mathbf{0 . 0 1 3 4}$
\end{tabular} \\
\hline $\mathrm{PC1}$ & $\begin{array}{l}\text { Seed origin } \\
\text { Mom }^{\mathrm{a}} \\
\text { Dad }^{\mathrm{a}} \\
\text { Destination site } \\
\text { Origin } \times \text { site } \\
\text { Mom } \times \text { Dad }^{\mathrm{a}}\end{array}$ & $\begin{array}{l}\mathbf{1}, \mathbf{1 0 . 5} \\
1 \\
1 \\
\mathbf{2}, \mathbf{1 0 2} \\
2,102 \\
\mathbf{1}\end{array}$ & $\begin{array}{l}7.52 \\
\\
\\
4.24 \\
1.68 \\
\end{array}$ & $\begin{array}{l}1.3 \\
0\end{array}$ & $\begin{array}{l}\mathbf{0 . 0 2 0} \\
0.127 \\
0.5 \\
\mathbf{0 . 0 1 7} \\
0.191 \\
\mathbf{0 . 0 4 4}\end{array}$ \\
\hline PC2 & $\begin{array}{l}\text { Seed origin } \\
\text { Mom }^{\mathrm{a}} \\
\text { Dad }^{\mathrm{a}} \\
\text { Destination site } \\
\text { Origin } \times \text { site } \\
\text { Mom } \times \text { Dad }^{\mathrm{a}}\end{array}$ & $\begin{array}{l}1,14 \\
1 \\
\mathbf{1} \\
2,110 \\
2,110 \\
1\end{array}$ & $\begin{array}{l}0.00 \\
1.06\end{array}$ & $\begin{array}{l}0.9 \\
\mathbf{3 . 9}\end{array}$ & $\begin{array}{l}0.150 \\
0.171 \\
\mathbf{0 . 0 2 4} \\
0.9963 \\
0.350 \\
0.5\end{array}$ \\
\hline PC3 & $\begin{array}{l}\text { Seed origin } \\
\text { Mom }^{\mathrm{a}} \\
\text { Dad }^{\mathrm{a}} \\
\text { Destination site } \\
\text { Origin } \times \text { site } \\
\text { Mom } \times \text { Dad }^{\mathrm{a}}\end{array}$ & $\begin{array}{l}1,11.9 \\
1 \\
1 \\
\mathbf{2}, \mathbf{1 0 7} \\
\mathbf{2 , 1 0 7} \\
1\end{array}$ & $\begin{array}{r}2.38 \\
\\
\\
\mathbf{5 0 . 0 9} \\
\mathbf{5 . 2 7}\end{array}$ & $\begin{array}{l}0.1 \\
1\end{array}$ & $\begin{array}{l}0.149 \\
0.376 \\
0.159 \\
\mathbf{0 . 0 0 0 1} \\
\mathbf{0 . 0 0 7} \\
0.5\end{array}$ \\
\hline
\end{tabular}

Boldface type indicates $P<0.05$.

${ }^{\text {a }}$ Likelihood-ratio $\chi^{2}$ tests for random effects.

duction when planted in the dunes compared to the other two sites, and plants from Mussel Point had the lowest alkaloid production when planted at Mussel Point and highest at Bayshore (Fig. 2). Total alkaloids and PC1 also varied significantly between maternal lines depending on paternal parent, and there were significant paternal effects on PC2 (Table 4).

\subsection{Correlation of seed and leaf alkaloids}

There were no significant correlations between total alkaloids or any major individual alkaloid in seeds and leaves from full-siblings $(P>0.15$ for all comparisons). This result was consistent regardless of whether leaf alkaloids were pooled across all sites $(n=35)$ or only from the site of origin $(n=27)$. 


\subsection{Herbivory and alkaloids}

The density of leaf herbivores was influenced by the composition and/or concentration of alkaloids, while the density of bud and apical herbivores was not influenced by any measure of alkaloids (Table 5). Interestingly, the density of red and green leaf gallers (both Dasineura lupinorum) was differentially susceptible to alkaloids. While red leaf galls were reduced on plants with higher alkaloids and were not strongly dependent on alkaloid composition, green leaf galls were increased on plants with higher total alkaloids and were also affected by all measures of alkaloid composition. Both gallers were also more abundant on larger plants, and varied between sites. Red galls were most abundant at Bayshore and green galls were most abundant at Mussel Point, with low levels of both at the dunes (BS: red $2.37 \pm 0.27$, green $0.37 \pm 0.07$; MP: red $0.81 \pm 0.11$, green $2.39 \pm 0.21 ; \mathrm{D}$ : red $0.06 \pm 0.03$, green $0.10 \pm 0.03$ ). Fungal lesions were also reduced on plants with higher total alkaloids and were affected by two of the three principal components. However, apical flies and bud gallers were not affected by total alkaloids or alkaloid composition. Bud galls varied between sites (BS: $0.30 \pm 0.04$, MP: $0.56 \pm 0.07$, D: $0.04 \pm 0.02$ ) but were not influenced by other factors. Apical flies were the only herbivore that was sufficiently abundant to analyze for 2 years. Fly density was

Table 5

Effect of alkaloid profiles, total alkaloids, plant size and site on the abundance of five herbivore species. Plant size is from the year of data analyzed (1996 or 1997). $\chi^{2}$ values are based on Type 3 analysis for that factor; parameter estimates \pm standard errors are provided for significant quantitative sources. Degrees of freedom are 1 for all sources except 2 for site, and are 113 for all deviances except 81 for fungus

\begin{tabular}{|c|c|c|c|c|c|c|}
\hline \multirow[t]{2}{*}{ Source } & \multicolumn{2}{|c|}{ Red leaf galler 1996} & \multicolumn{2}{|c|}{ Green leaf galler 1996} & \multicolumn{2}{|l|}{ Fungus 1997} \\
\hline & $\overline{\chi^{2}}$ & Est. & $\overline{\chi^{2}}$ & Est. & $\overline{\chi^{2}}$ & Est. \\
\hline $\mathrm{PC} 1$ & $5.39^{*}$ & $11.4 \pm 4.97$ & $27.32^{* * * *}$ & $-19.53 \pm 3.93$ & $6.93^{* *}$ & $14.31 \pm 6.11$ \\
\hline $\mathrm{PC} 2$ & 2.11 & & $10.49^{* *}$ & $-2.5 \pm 0 . .84$ & 0.46 & \\
\hline PC3 & 1.87 & & $26.79^{* * * *}$ & $-11.24 \pm 2.3$ & $7.05^{* *}$ & $10.55 \pm 4.22$ \\
\hline Total alks. & $5.39^{*}$ & $-5.96 \pm 2.62$ & $27.74^{* * * *}$ & $10.03 \pm 1.98$ & $5.82 *$ & $-7.24 \pm 3.37$ \\
\hline Plant size & $21.63^{* * * *}$ & $\mathbf{1 . 0 2} \pm \mathbf{0 . 2 7}$ & $23.35^{* * * *}$ & $\mathbf{0 . 9 8} \pm \mathbf{0 . 2 3}$ & 0.00 & \\
\hline Site & $39.09^{* * * *}$ & $\mathrm{n} / \mathrm{a}$ & $31.20^{* * * *}$ & $\mathrm{n} / \mathrm{a}$ & 0.06 & \\
\hline Deviance & $184.63+$ & & $223.75+$ & & $36.43+$ & \\
\hline Source & Apical fly 19 & & Apical fly 1997 & & Bud galler 1996 & \\
\hline PC1 & 2.75 & & 0.65 & & 0.01 & \\
\hline PC2 & 1.25 & & 0.72 & & 0.38 & \\
\hline $\mathrm{PC} 3$ & 1.46 & & 0.48 & & 0.68 & \\
\hline Total alks. & 2.81 & & 1.09 & & 0.03 & \\
\hline Plant size & $21.32^{* * * * *}$ & $\mathbf{0 . 7 0} \pm \mathbf{0 . 1 7}$ & 0.04 & & 0.04 & \\
\hline Site & 1.46 & & $9.93^{* *}$ & $\mathrm{n} / \mathrm{a}$ & $12.31^{* *}$ & $\mathrm{n} / \mathrm{a}$ \\
\hline Deviance & 106.98 & & 146.13 & & 110.86 & \\
\hline
\end{tabular}

${ }^{*} P<0.05 ;{ }^{* *} P<0.01 ;{ }^{* * *} P<0.001 ;{ }^{* * * *} P<0.0001$.

+ , Scale parameter was estimated by the square root of deviance/df to correct for over- or underdispersion. 
influenced only by plant size in 1996 and only by site in 1997 (BS: $0.95 \pm 0.07$, MP: $0.45 \pm 0.05$, D: $0.45 \pm 0.04)$.

\section{Discussion}

Seed alkaloid profiles varied significantly between populations, and also between maternal parents within population (Fig. 1). While there were no significant paternal effects on total alkaloids or any principal component, suggesting a lack of additive genetic variance for these traits, there were significant maternal $\times$ paternal interactions on all alkaloid measures (Table 2). Thus, the alkaloid profile of a seed depends on non-additive effects of both parents as well as on the origin population.

Long-distance dispersal is more likely to happen via pollen flow than seed dispersal, and thus an interaction between paternal and progeny alkaloids may have important fitness consequences. Rodent predation of lupine seeds can be as high as 85\% (Maron and Simms, 1997) and can limit plant recruitment at Bodega Bay (Maron and Simms, 2001). In a previous study, rodent predation was highest in the dunes (Maron and Simms, 1997), the site whose seeds had the lowest total alkaloids in our study. This suggests at least a correlational relationship between low alkaloids and high rodent predation. In populations where most plants have low alkaloids, high-alkaloid offspring may be achieved primarily by gene flow from other populations (paternal effects), and/or by non-additive effects of parents on offspring phenotype. Thus, maternal $\times$ paternal interactions on offspring seed alkaloids may have significant consequences for early establishment of lupines.

Leaf alkaloid profiles and composition affected the density of leaf herbivores, but not apical or bud herbivores. The leaf galler Dasineura lupinorum was influenced by alkaloids while the congeneric bud galler $D$. lupini was not, suggesting that even closely related herbivores from different guilds may exert differential selection on the production or composition of plant chemical defense. Even different forms of the same herbivore species may respond in opposite directions to defense traits. Red leaf galls were reduced and green leaf galls were increased on high alkaloid plants (Table 1), and green leaf galls were more strongly affected by alkaloid composition than red leaf galls. Thus, different forms of the same herbivore may select in opposite directions on the production of plant defense. Additionally, green leaf galls were reduced on plants with high values of all principal components, whereas fungal lesions increased on plants with high values of principal components 1 and 3. The outcome of selection on defense production and composition in a multispecies environment may therefore be highly dependent on the community composition at a particular site, as well as on the fitness impacts of different herbivores. A caveat to these results is that our study documents a correlational rather than causational relationship. Variation in herbivore density and defense production may both be affected by other, unmeasured environmental factors; however, this caveat applies to most field-based studies of plant resistance.

While quinolizidine alkaloids have been shown to have general deterrrent and toxic properties to a wide range of organisms (Wink, 1993), this is the first report 
we are aware of that relates alkaloids to resistance to a galling insect. Previous studies have found no relation between tannins and galls (Espirito-Santo and Fernandes, 1998), but a positive relationship between phenolglucoside concentration and gall abundance in willow hybrids (Soetens et al., 1991). Maddox and Root (1987) found consistent heritable resistance for multiple species of stem galling insects but not other herbivore guilds, although traits associated with resistance were not identified. Although stem and bud gallers can have clear impacts on plant fitness (Quiring and McKinnon, 1999), the relationship between leaf gallers and plant fitness is not as clear. There are still remarkably few studies that have demonstrated selection by herbivores on specific plant chemical defenses (but see Mauricio and Rausher, 1997; Shonle and Bergelson, 2000). Given the relationship between leaf gallers and alkaloid traits in this study, it would be worthwhile to determine whether leaf gallers have impacts on plant fitness that would translate to selection for defense traits.

Additionally, there are few studies that have related herbivory to defense composition rather than concentration. A lack of relationship between defense profiles and herbivory has been found for specialist herbivores on Senecio species (Macel et al., 2002) and a variety of specialist and generalist herbivores on Brassica oleracea (Moyes et al., 2000). However, in wild parsnip (Pastinaca sativa), populations varied significantly in the relative proportions of four furanocoumarins (Berenbaum and Zangerl, 1996) in a site-specific pattern that generally matched the ability of the specialist herbivore parsnip webworm (Depressaria pastinacella) to detoxify these compounds, suggesting a coevolutionary process mediated by defense composition. Diversity of compounds can also play a role in defense; damage by the specialist herbivore Pieris rapae induced the production of a greater diversity, but not higher concentration, of glucosinolate defenses in Lepidium virginicum. This induction decreased subsequent feeding by a generalist herbivore (Agrawal, 2000). Such diversity of defense compounds is generally thought to increase herbivore resistance, but this idea has not been broadly tested (Berenbaum and Zangerl, 1996; Agrawal, 2000, and references therein).

We found no correlation between individual or total alkaloids of seeds and fullsib 2.5-year-old plants. This lack of relationship suggests that (a) separate processes mediate the production of alkaloids in seed and leaves, or (b) an underlying genetic correlation between seed and leaf alkaloids is masked by environmental variability. It is perhaps unsurprising to find no relationship between seed alkaloids and leaf alkaloids, given that seed traits are likely to be strongly influenced by maternal effects that diminish over the life of the plant (Roach and Wulff, 1987). Resource or water availability (Gershenzon, 1984), herbivory (Harrison and Karban, 1986), and other environmental factors could influence defense production in adult plants and obscure any effects of genotype or maternal environment.

We found consistently strong maternal effects on seed alkaloids but not leaf alkaloids. Environmental maternal effects can influence a variety of plant traits, including emergence time, rates of leaf development and juvenile size (Michaels et al., 1988; Helenurm and Schaal, 1996; Stanton and Galen, 1997). In the wild radish Raphanus raphanistrum, herbivory on maternal plants increased allocation 
to chemical defense in seedlings (Agrawal et al., 1999), but these effects became less pronounced in older plants, where defenses were more strongly determined by offspring environment (Agrawal, 2001, 2002). Maternal environmental effects are generally most pronounced early in the progeny's life and become weaker with age (Roach and Wulff, 1987; Miao et al., 1991), consistent with our results in the current study.

Destination site had strong and consistent effects on leaf alkaloid concentration and profiles, indicating that environmental factors affect the expression of alkaloid content. Similar results were found in two Delphinium species whose alkaloid profiles were distinct in the field; when plants of both species were transplanted to the same site, alkaloid variation disappeared (Ralphs and Gardner, 2001). Other studies comparing the relative role of plant genotype and environment on herbivore resistance have implicated either plant genotype (Abrahamson et al., 1988; Hakulinen et al., 1995; Horner, 1999; Osier and Lindroth, 2001) or environment (Orians et al., 1996; Rossi and Stiling, 1998) as the primary source of variation, although interactions between genotype and environment can also be significant (Maddox and Cappuccino, 1986). Most of these studies were done with clonal plants, which may overestimate the importance of genetic variation in sexually reproducing plants.

Additionally, population-level variation in alkaloid profiles depended on destination site. Plants from Mussel Point had equivalent total alkaloids with Dunes plants when grown at Bayshore, but lower alkaloids than Dunes plants when grown at the other two sites (Fig. 2). Thus, defensive phenotypes depended on genetic differences between populations, the environment where the seed grew, and interactions between these factors. We are aware of few other studies that have examined the potential for interactions between origin population and destination site on plant defensive profiles; this research indicates that defense profiles of genotypes in new environments cannot be predicted based on profiles in other environments. In addition, the non-additive parental effects on alkaloid profiles suggest the potential to create novel phenotypes with certain combinations of parents. While L. arboreus seeds do not disperse far (Maron and Simms, 1997), pollen flow could provide a mechanism by which genetic variation is dispersed to novel environments and/or novel maternal genotypes.

We found that alkaloid content of both seeds and leaves varied between origin populations. Such differentiation is somewhat surprising since other research at the same site suggested that gene flow is not restricted between these populations (Kittelson and Maron, 2001). Therefore, it seems likely that selection produced site-specific patterns in lupine traits, including alkaloids. The selective agents responsible for producing the local differentiation that we observed remain to be identified, but may involve a combination of edaphic and biotic pressures unique to each area. Life history traits, including plant size and fecundity, also varied substantially across the Bodega Marine Reserve, among families from different origins, and among different maternal parents (Kittelson and Maron, 2001). Thus, selection may act on a suite of correlated traits that vary among populations and among parents. 
Although we detected maternal $\times$ paternal interactions on leaf alkaloids, we did not find consistent effects of maternal or paternal family. Our inability to detect family effects may be due to smaller sample sizes caused by higher mortality and therefore lower statistical power. In the first 2 years, plants growing at Bayshore and in the Dunes suffered considerably more mortality than at Mussel Point. Consequently, there were fewer representatives at these sites to test the effect of family identity on alkaloid content. Moreover, the total number of maternal and paternal half-sib families that were created in each origin was relatively low, especially for confidently detecting paternal effects. The great environmental variation in field sites may reduce our ability to detect genetic effects, but this is the appropriate environment to test for heritability because organisms normally experience selection in field conditions rather than controlled environments (Campbell, 1996).

In conclusion, we found that genetic factors, environmental factors, and their interaction all play a role in determining alkaloid profiles of a perennial lupine. Leaf herbivores were generally affected by alkaloid concentration and composition while apical and bud herbivores were not; however, even two variations of the same leaf herbivore had opposite relationships with alkaloid concentration. These results highlight the complexity of interactions between herbivores and plant defenses and indicate that measuring selection for defense traits may not be straightforward in natural environments that include multiple herbivore guilds, and where phenotypic traits are determined by a complicated suite of both environmental and genetic factors.

\section{Acknowledgements}

We thank M. Wink for identifying major alkaloids, and Barbara L. Bentley and Michael Ziebell for invaluable assistance with alkaloid quantification, including the use of B. L. Bentley's gas chromatograph (funded by USDA/NRI Grant 9401661). We thank Joy Diaz, Jill Johnston, Jeanne Robertson for field assistance, Peter Connors for reserve access, Eric Smith and Bo Jin of the Virginia Tech Statistical Consulting Center for statistical advice, Susan Harrison for use of tent cages, and Becky Irwin, John Maron, Paige Warren and two anonymous reviewers for their comments on the manuscript. This research was funded by the Bodega Field Conference, Jastro-Shields Fund and Pro-Femina Research Consortium at U. C. Davis for PMK and NSF DEB98-00885 and the Virginia Tech Dept. of Biology for LSA.

\section{References}

Abrahamson, W.G., Anderson, S.S., McCrea, K.D., 1988. Effects of manipulation of plant carbon nutrient balance on tall goldenrod resistance to a gallmaking herbivore. Oecologia 77, 302-306.

Adler, F.R., Karban, R., 1994. Defended fortresses or moving targets?: another model of inducible defenses inspired by military metaphors. American Naturalist 144, 813-832. 
Adler, L.S., Wink, M., 2001. Transfer of alkaloids from hosts to hemiparasites in two Castilleja-Lupinus associations: analysis of floral and vegetative tissues. Biochemical Systematics and Ecology 29, 551-561.

Agrawal, A.A., 1998. Leaf damage and associated cues induced aggressive ant recruitment in a neotropical ant-plant. Ecology 79, 2100-2112.

Agrawal, A.A., 2000. Benefits and costs of induced plant defense for Lepidium virginicum (Brassicaceae). Ecology 81, 1804-1813.

Agrawal, A.A., 2001. Transgenerational consequences of plant responses to herbivory: An adaptive maternal effect? American Naturalist 157, 555-569.

Agrawal, A.A., 2002. Herbivory and maternal effects: Mechanisms and consequences of transgenerational induced plant resistance. Ecology 83, 3408-3415.

Agrawal, A.A., Laforsch, C., Tollrian, R., 1999. Transgenerational induction of defences in animals and plants. Nature 401, 60-63.

Agren, J., Schemske, D.W., 1993. The cost of defense against herbivores: an experimental study of trichome production in Brassica rapa. American Naturalist 141, 338-350.

Berenbaum, M.R., Zangerl, A.R., 1992. Genetics of secondary metabolism and herbivore resistance in plants. In: Rosenthal, G.A., Berenbaum, M.R. (Eds.), Herbivores: Their Interactions with Secondary Plant Metabolites. Academic Press, San Diego, pp. 415-438.

Berenbaum, M.R., Zangerl, A.R., 1996. Phytochemical diversity: adaptation or random variation? In: Romeo, J.T., Saunders, I.A., Barbosa, P. (Eds.), Phytochemical Diversity and Redundancy in Ecological Interactions. Plenum Press, New York, pp. 1-24.

Berenbaum, M.R., Zangerl, A.R., 1998. Chemical phenotype matching between a plant and its insect herbivore. Proceedings of the National Academy of Sciences 95, 13743-13748.

Berenbaum, M.R., Zangerl, A.R., Lee, K., 1989. Chemical barriers to adaptation by a specialist herbivore. Oecologia 80, 501-506.

Berenbaum, M.R., Zangerl, A.R., Nitao, J.K., 1986. Constraints on chemical evolution: wild parsnips and the parsnip webworm. Evolution 40, 1215-1228.

Bowers, M.D., Collinge, S.K., Gamble, S.E., Schmitt, J., 1992. Effects of genotype, habitat, and seasonal variation on iridoid glycoside content of Plantago lanceolata (Plantaginaceae) and the implications for insect herbivores. Oecologia 91, 201-207.

Brown, D.G., 1988. The cost of plant defense: An experimental analysis with inducible proteinase inhibitors in tomato. Oecologia 76, 467-470.

Campbell, D.R., 1996. Evolution of floral traits in a hermaphroditic plant: Field measurements of heritabilitles and genetic correlations. Evolution 50, 1442-1453.

Carey, D.B., Wink, M., 1994. Elevational variation of quinolizidine alkaloid contents in a lupine (Lupinus argenteus) of the Rocky Mountains. Journal of Chemical Ecology 20, 849-857.

Davison, E.D., Barbour, M.G., 1977. Germination, establishment and demography of coastal bush lupine (Lupinus arboreus) at Bodega Head, California. Ecology 58, 592-600.

Dement, W.A., Mooney, H.A., 1974. Seasonal variation in the production of tannins and cyanogenic glucosides in the chaparral shrub, Heteromeles arbutifolia. Oecologia 15, 65-76.

Denno, R.F., McClure, M.S. (Eds.), 1983. Variable Plants and Herbivores in Natural and Managed Systems. Academic Press, New York.

Dolinger, P.M., Ehrlich, P.R., Fitch, W.L., Breedlove, D.E., 1973. Alkaloid and predation patterns in Colorado lupine populations. Oecologia 13, 191-204.

Espirito-Santo, M.M., Fernandes, G.W., 1998. Abundance of Neopelma baccharidis (Homoptera : Psyllidae) galls on the dioecious shrub Baccharis dracunculifolia (Asteraceae). Environmental Entomology 27, 870-876.

Falconer, D.S., 1989. Introduction to Quantitative Genetics, 3rd edition . Longman Scientific \& Technical, New York.

Feeny, P., 1970. Seasonal changes in oak leaf tannins and nutrients as a cause of spring feeding by winter moth caterpillars. Ecology 51, 565-581.

Fernandes, G.W., Negreiros, D., 2001. The occurrence and effectiveness of hypersensitive reaction against galling herbivores across host taxa. Ecological Entomology 26, 46-55. 
Gershenzon, J., 1984. Changes in the levels of plant secondary metabolites under water and nutrient stress. In: Timmermann, B.N., Steelink, C., Loewus, F.A. (Eds.), Phytochemical Adaptations to Stress. Plenum Press, New York, pp. 273-321.

Hagele, B.F., Rowell-Rahier, M., 1999. Genetic and environmental-based variability in secondary metabolite leaf content of Adenostyles alliariae and A. alpina (Asteraceae). A test of the resource availability hypothesis. Oikos $85,234-246$.

Hakulinen, J., Julkunentiitto, R., Tahvanainen, J., 1995. Does nitrogen fertilization have an impact on the trade-off between willow growth and defensive secondary metabolism. Trees-Structure and Function 9, 235-240.

Harrison, S., Karban, R., 1986. Effects of an early-season folivorous moth on the success of a later-season species, mediated by a change in the quality of the shared host, Lupinus arboreus Sims. Oecologia $69,354-359$

Harrison, S., Maron, J.L., 1995. Impacts of defoliation by tussock moths (Orgyia vetusta) on the growth and reproduction of bush lupine (Lupinus arboreus). Ecological Entomology 20, 223-229.

Helenurm, K., Schaal, B.A., 1996. Genetic and maternal effects on offspring fitness in Lupinus texensis (Fabaceae). American Journal of Botany 83, 1596-1608.

Hickman, J., 1993. The Jepson Manual. . University of California Press, Berkeley.

Horner, J.D., 1999. Influence of plant genotype and early-season water deficits on oviposition preference and offspring performance in Eurosta solidaginis (Diptera : Tephritidae). American Midland Naturalist $142,162-172$.

Hougen-Eitzman, D., Rausher, M.D., 1994. Interactions between herbivorous insects and plant-insect coevolution. American Naturalist 143, 677-697.

Hummelbrunner, L.A., Isman, M.B., 2001. Acute, sublethal, antifeedant, and synergistic effects of monoterpenoid essential oil compounds on the tobacco cutworm, Spodoptera litura (Lep., Noctuidae). Journal of Agricultural and Food Chemistry 49, 715-720.

Iwao, K., Rausher, M.D., 1997. Evolution of plant resistance to multiple herbivores: Quantifying diffuse coevolution. American Naturalist 149, 316-335.

Johnson, N.D., Rigney, L.P., Bentley, B.L., 1989. Short-term induction of alkaloid production in lupines: differences between nitrogen-fixing and nitrogen-limited plants. Journal of Chemical Ecology $15,2425-2434$.

Juenger, T., Bergelson, J., 1997. Pollen and resource limitation of compensation to herbivory in scarlet gilia, Ipomopsis aggregata. Ecology 78, 1684-1695.

Karban, R., Agrawal, A.A., Mangel, M., 1997. The benefits of induced defenses against herbivores. Ecology 78, 1351-1355.

Karban, R., Baldwin, I.T., 1997. Induced Responses to Herbivory. The University of Chicago Press, Chicago.

Kittelson, P.M., 1998. Genetic structure in a population of bush lupine (Lupinus arboreus): influence of mating system, gene flow and selection. PhD, University of California, Davis.

Kittelson, P.M., Maron, J.L., 2000. Outcrossing rate and inbreeding depression in the perennial yellow bush lupine, Lupinus arboreus (Fabaceae). American Journal of Botany 87, 652-660.

Kittelson, P.M., Maron, J.L., 2001. Fine-scale genetically based differentiation of life-history traits in the perennial shrub Lupinus arboreus. Evolution 55, 2429-2438.

Lindroth, R.L., Scriber, J.M., Hsia, M.T.S., 1988. Chemical ecology of the tiger swallowtail: mediation of host use by phenolic glycosides. Ecology 69, 814-822.

Louda, S.M., Potvin, M.A., 1995. Effect of inflorescence-feeding insects on the demography and lifetime fitness of a native plant. Ecology 76, 229-245.

Macel, M., Klinkhamer, P.G.L., Vrieling, K., van der Meijden, E., 2002. Diversity of pyrrolizidine alkaloids in Senecio species does not affect the specialist herbivore Tyria jacobaeae. Oecologia 133, 541550.

Maddox, G.D., Cappuccino, N., 1986. Genetic determination of plant susceptibility to an herbivorous insect depends on environmental context. Evolution 40, 863-866.

Maddox, G.D., Root, R.B., 1987. Resistance to 16 diverse species of herbivorous insects within a population of goldenrod, Solidago altissima: genetic variation and heritability. Oecologia 72, 8-14. 
Mankinen, C.B., Harding, J., Elliot, M., 1975. Genetics of Lupinus. VIII. Variations in the occurence of alkaloids in natural populations of Lupinus nanus. Taxon 24, 415-429.

Maron, J.L., 1998. Insect herbivory above and below ground: Individual and joint effects on plant fitness. Ecology 79, 1281-1293.

Maron, J.L., 2001. Intraspecific competition and subterranean herbivory: individual and interactive effects on bush lupine. Oikos 92, 178-186.

Maron, J.L., Harrison, S., Greaves, M., 2001. Origin of an insect outbreak: escape in space or time from natural enemies? Oecologia 126, 595-602.

Maron, J.L., Simms, E.L., 1997. Effect of seed predation on seed bank size and seedling recruitment of bush lupine (Lupinus arboreus). Oecologia 111, 76-83.

Maron, J.L., Simms, E.L., 2001. Rodent-limited establishment of bush lupine: field experiments on the cumulative effect of granivory. Journal of Ecology 89, 578-588.

Marquis, R., 1992. Selective impact of herbivores. In: Fritz, R., Simms, E. (Eds.), Plant Resistance to Herbivores and Pathogens: Ecology, Evolution and Genetics. The University of Chicago Press, Chicago, pp. 300-325.

Mauricio, R., Rausher, M.D., 1997. Experimental manipulation of putative selective agents provides evidence for the role of natural enemies in the evolution of plant defense. Evolution 51, 1435-1444.

Miao, S.L., Bazzaz, F.A., Primack, R.B., 1991. Persistence of maternal nutrient effects in Plantago major: The third generation. Ecology 72, 1634-1642.

Michaels, H.J.B., Benner, B., Hartgerink, A.P., Lee, T.D., Rice, S., Willson, M.F., Bert, R.F., 1988. Seed size variation, magnitude, distribution, and ecological correlates. Evolutionary Ecology 2, 157-166.

Moyes, C.L., Collin, H.A., Britton, G., Raybould, A.E., 2000. Glucosinolates and differential herbivory in wild populations of Brassica oleracea. Journal of Chemical Ecology 26, 2625-2641.

Nitao, J.K., Zangerl, A.R., Berenbaum, M.R., 2002. CNB: requiescat in pace? Oikos 98, 540-546.

Nuñez-Farfán, J., Dirzo, R., 1994. Evolutionary ecology of Datura stramonium L in central Mexico: natural selection for resistance to herbivorous insects. Evolution 48, 423-436.

Ollerstam, O., Rohfritsch, O., Hoglund, S., Larsson, S., 2002. A rapid hypersensitive response associated with resistance in the willow Salix viminalis against the gall midge Dasineura marginemtorquens. Entomologia Experimentalis et Applicata 102, 153-162.

Orians, C.M., Roche, B.M., Fritz, R.S., 1996. The genetic basis for variation in the concentration of phenolic glycosides in Salix sericea: An analysis of heritability. Biochemical Systematics and Ecology 24, 719-724.

Osier, T.L., Lindroth, R.L., 2001. Effects of genotype, nutrient availability, and defoliation on aspen phytochemistry and insect performance. Journal of Chemical Ecology 27, 1289-1313.

Preisser, E.L., 2003. Field evidence for a rapidly cascading underground food web. Ecology 84, 869-874.

Quiring, D.T., McKinnon, M.L., 1999. Why does early-season herbivory affect subsequent budburst? Ecology 80, 1724-1735.

Ralphs, M.H., Gardner, D.R., 2001. Alkaloid levels in duncecap (Delphinium occidentale) and tall larkspur (D. barbeyi) grown in reciprocal gardens: separating genetic from environmental influences. Biochemical Systematics and Ecology 29, 117-124.

Roach, D.A., Wulff, R.D., 1987. Maternal effects in plants. Annual Review of Ecology and Systematics 18, 209-235.

Roche, B.M., Fritz, R.S., 1997. Genetics of resistance of Salix sericea to a diverse community of herbivores. Evolution 51, 1490-1498.

Rosenthal, G., Berenbaum, M. (Eds.), 1991. Herbivores: Their Interactions with Secondary Plant Metabolites, 2nd edn. Academic Press, San Diego, CA.

Rossi, A.M., Stiling, P., 1998. The interactions of plant clone and abiotic factors on a gall-making midge. Oecologia 116, 170-176.

SAS-Institute, 1999. SAS/STAT User's guide, release 8 ed. SAS Institute, Cary, NC.

Schultz, J.C., Nothnagle, P.J., Baldwin, I.T., 1982. Seasonal and individual variation in leaf quality of two northern hardwoods tree species. American Journal of Botany 69, 753-759.

Sharma, S., 1996. Multivariate Statistics. . John Wiley \& Sons, New York. 
Shaw, R.G., 1987. Maximum-likelihood approaches applied to quantitative genetics of natural populations. Evolution 41, 812-826.

Shaw, R.G., Platenkamp, G.A.J., Shaw, F.H., Podolsky, R.H., 1995. Quantitative genetics of response to competitors in Nemophila menziesii: a field experiment. Genetics 139, 397-406.

Shonle, I., Bergelson, J., 2000. Evolutionary ecology of the tropane alkaloids of Datura stramonium L. (Solanaceae). Evolution 54, 778-788.

Skaanild, M.T., Friis, L.C., Brimer, L., 2001. Interplant alkaloid variation and Senecio vernalis toxicity in cattle. Veterinary and Human Toxicology 43, 147-151.

Soetens, P., Rowellrahier, M., Pasteels, J.M., 1991. Influence of phenolglucosides and trichome density on the distribution of insect herbivores on willows. Entomologia Experimentalis et Applicata 59, $175-187$.

Stanton, M.L., Galen, C., 1997. Life on the edge: Adaptation versus environmentally mediated gene flow in the snow buttercup, Ranunculus adoneus. American Naturalist 150, 143-178.

Stinchcombe, J.R., Rausher, M.D., 2001. Diffuse selection on resistance to deer herbivory in the ivyleaf morning glory, Ipomoea hederacea. American Naturalist 158, 376-388.

Stout, M.J., Bostock, R.M., 1999. Specificity of induced responses to arthrophods and pathogens. In: Agrawal, A.A., Tuzun, S., Bent, E. (Eds.), Induced Plant Defenses against Pathogens and Herbivores. APS Press, St. Paul, MN, pp. 183-210.

Strong, D.R., Maron, J.L., Connors, P.G., Whipple, A., Harrison, S., Jefferies, R.L., 1995. High mortality, fluctuation in numbers, and heavy subterranean insect herbivory in bush lupine, Lupinus arboreus. Oecologia 104, 85-92.

Strong, D.R., Whipple, A.V., Child, A.L., Dennis, B., 1999. Model selection for a subterranean trophic cascade: Root- feeding caterpillars and entomopathogenic nematodes. Ecology 80, 2750-2761.

Thompson, J.N., 1997. Evaluating the dynamics of coevolution among geographically structured populations. Ecology 78, 1619-1623.

van Dam, N.M., Vrieling, K., 1994. Genetic variation in constitutive and inducible pyrrolizidine alkaloid levels in Cynoglossum officinale L. Oecologia 99, 374-378.

Wink, M., 1992. The role of quinolizidine alkaloids in plant-insect interactions. In: Bernays, E. (Ed.), Insect-Plant Interactions. CRC Press, Boca Raton, pp. 133-169.

Wink, M., 1993. Allelochemical properties or the raison d'être of alkaloids. In: Cordell, G.A. (Ed.), The Alkaloids. Academic Press, Inc, San Diego, pp. 1-118.

Wink, M., Carey, D.B., 1994. Variability of quinolizidine alkaloid profiles of Lupinus argenteus (Fabaceae) from North America. Biochemical Systematics and Ecology 22, 663-669.

Wink, M., Latz-Bruning, B., 1995. Allelopathic properties of alkaloids and other natural products. In: Inderjit, Dakshini, K.M.M., Einhellig, F.A. (Eds.), Allelopathy: Organisms, Processes and Applications. American Chemical Society, Washington DC, pp. 117-126.

Wink, M., Meissner, C., Witte, L., 1995. Patterns of quinolizidine alkaloids in 56 species of the genus Lupinus. Phytochemistry 38, 139-153.

Wittstock, U., Gershenzon, J., 2002. Constitutive plant toxins and their role in defense against herbivores and pathogens. Current Opinion in Plant Biology 5, 300-307. 